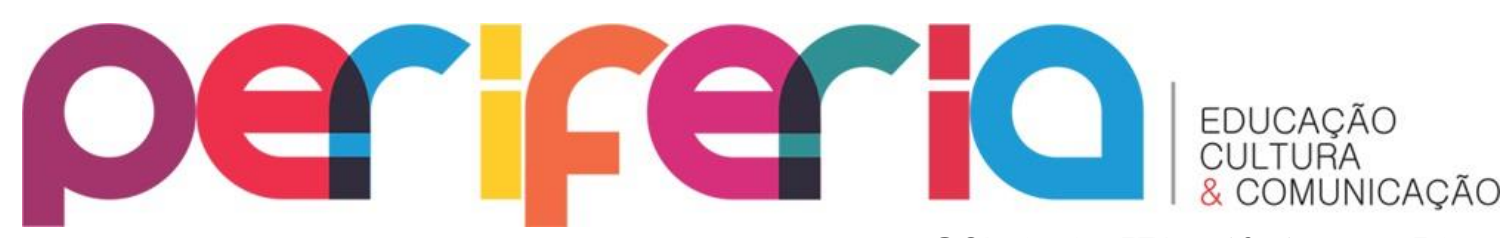

\title{
MEMÓRIAS CENTENÁRIAS: JOÃOZINHO DA GOMEIA E O MUSEU VIVO DO SÃO BENTO
}

Nielson Bezerra ${ }^{1}$

\section{Resumo}

O Museu Vivo do São Bento organizou uma série de atividades em comemoração ao Centenário de Joãozinho da Gomeia, o mais famoso sacerdote de candomblé do Brasil durante o tempo em que ele viveu na cidade de Duque de Caxias. Embora ele comumente seja reconhecido como o "rei do candomblé", suas memórias na cidade de Duque de Caxias passam por um processo de disputas entre a lembrança e o esquecimento, configurando uma "gangorra da memória" nas narrativas da cidade. O Centenário de Joãozinho da Gomeia (1914-2014) buscou um debate amplo com a cidade através de uma iniciativa de monumentalização de sua memória. Esse artigo transcorre por esse processo problematizando a ideia de memória de resistência e longevidade, o que se caracteriza como uma "memória centenária".

Palavras chaves: Joãozinho da Gomeia; Museu Vivo do São Bento; Memória; Esquecimentos; Duque de Caxias/RJ.

\section{CENTENARY MEMORIES: JOÃOZINHO DA GOMEIA AND THE MUSEU VIVO DO SÃO BENTO}

\section{Abstract}

The Museu Vivo do São Bento organized a series of activities in celebration of the Centenary of Joãozinho da Gomeia, the most famous candomblé priest in Brazil during the time he lived in the city of Duque de Caxias. Although Joãozinho da Gomeia is commonly recognized as the "king of candomblé", his memories in the city of Duque de Caxias go through a process of disputes between remembering and forgetting, configuring a "seesaw of memory" in the city's narratives. The Centenary of Joãozinho da Gomeia (1914-2014) sought a broad debate with the city with an initiative to monumentalize his memory. This article goes through this process, problematizing the idea of memory of resistance and longevity, which is characterized as a "centennial memory".

Key-words: Joãozinho da Gomeia; Museu Vivo do São Bento; Memory; Forgetting; Duque de Caxias/RJ.

\footnotetext{
${ }^{1}$ Professor do Programa de Pós-Graduação em Educação, Cultura e Comunicações em Periferias (PPGECC) da Faculdade de Educação da Baixada Fluminense (FEBF/UERJ). ORCID iD: https://orcid.org/0000-00032211-5389. E-mail: bezerranielson@hotmail.com
} 


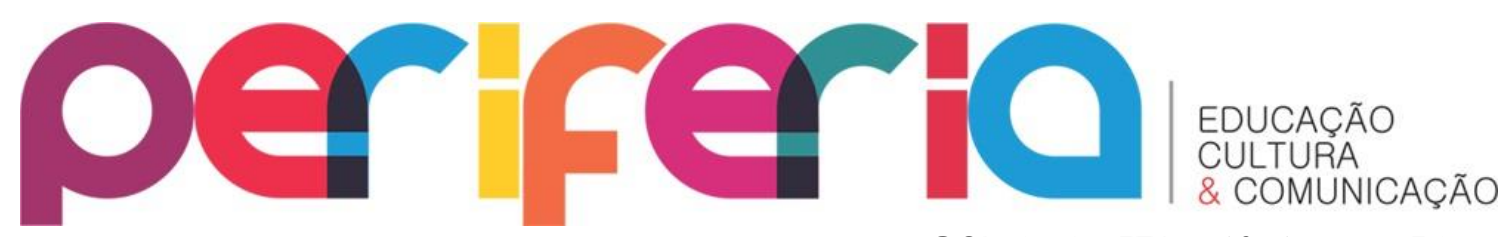

ISSN:1984-9540

DOI: $10.12957 /$ periferia.2020.54883

MEMORIAS CENTENARIAS:

JOÃOZINHO DA GOMEIA Y EL MUSEO VIVO DE SÃO BENTO

\section{Resumen}

El Museo Vivo de São Bento organizó una serie de actividades en celebración del Centenario de Joãozinho da Gomeia, el sacerdote candomblé más famoso de Brasil durante el tiempo que vivió en la ciudad de Duque de Caxias. Aunque Joãozinho da Gomeia es comúnmente reconocido como el "rey del candomblé", sus recuerdos en la ciudad del Duque de Caxias atraviesan un proceso de disputas entre recordar y olvidar, configurando un "balancín de la memoria" en las narrativas de la ciudad. El Centenario de Joãozinho da Gomeia (1914-2014) buscó un amplio debate con la ciudad con una iniciativa para monumentalizar su memoria. Este artículo pasa por este proceso, problematizando la idea de memoria de resistencia y longevidad, que se caracteriza como una "memoria centenaria".

Palabras-claves: Joãozinho da Gomeia; Museo Vivo de São Bento; Memoria; Olvidar; Duque de Caxias.

\section{Introdução}

A cidade de Duque de Caxias, situada na Baixada Fluminense, na periferia da cidade do Rio de Janeiro, tem uma população de 924.624, segundo as estimativas para o ano de 2020. De acordo com o último censo, 50,7\% da população se auto declarou como pretos e pardos, formando uma maioria de negros entre os seus moradores (IBGE, 2010). Considerando esses dados, já se pode afirmar que Duque de Caxias é uma das muitas cidades negras do Brasil. Contudo, bem sabemos que essa categorização não carece apenas de dados quantitativos, mas também de referências culturais e, sobretudo de uma dinâmica de pertencimento e identidades que se dá não apenas pela auto declaração de indivíduos, mas pelas memórias coletivas e institucionais de uma cidade. Desde o século XVII, pelo menos, que temos uma maioria de negros na população do território da cidade de Duque de Caxias. Porém, não há uma cultura de valorização da população negra nas políticas públicas da cidade, isto é, a memória institucional de Duque de Caxias, ao longo de sua história, não tem buscado evidenciar os processos e representantes negros que nasceram e 


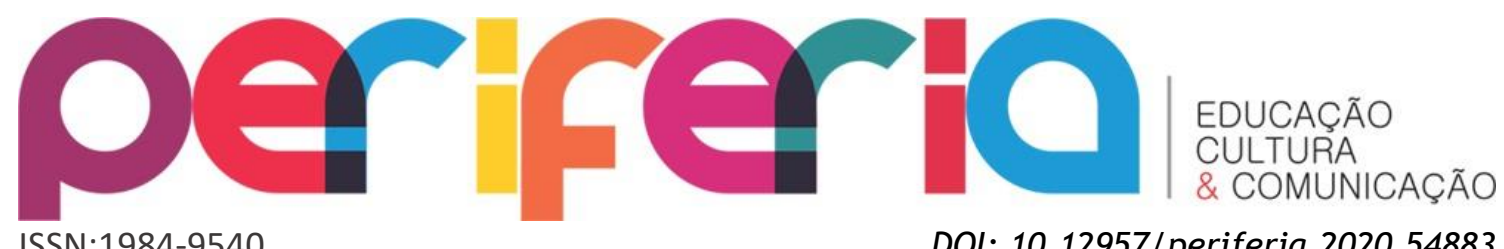

ISSN:1984-9540

DOI: $10.12957 /$ periferia.2020.54883 viveram em seu território desde os tempos da colonização portuguesa. Situado em um debate entre raça e classe (FERNANDES, 1965), esse artigo tem por objetivo pensar as memórias da cidade de Duque de Caxias através das comemorações do Centenário de Joãozinho da Gomeia organizadas pelo Museu Vivo do São Bento, ao longo do ano de 2014.

Este artigo busca problematizar Joãozinho da Gomeia como uma referência dos indicadores empíricos da memória da cidade de Duque de Caxias, mesmo quando suas lembranças são empurradas para uma fase de retração. Nesses momentos, as hierarquizações da memória estruturada e classificada na consciência coletiva da cidade. As contradições dos processos de monumentalização da cidade de Duque de Caxias demonstra-se contraditórios quando em uma maioria de negros e negras, a cidade tem sempre monumentalizado uma parte da história e da memória local que tem sua matriz na colonização portuguesa. É claro que é possível identificar algumas exceções. A memória de Joãozinho da Gomeia é uma delas. Porém, nenhuma dessas exceções se configura pela constância nas iniciativas dos poderes constituídos da cidade.

\section{Joãozinho da Gomeia e a "gangorra da memória"}

Joãozinho da Gomeia (1914-1971) é um expoente da cultura negra de Duque de Caxias, mas a sua história e o seu legado sempre se situaram entre a lembrança e o esquecimento nas narrativas da cidade. Desde a última década do século $X X$, suas memórias aparecem e ocupam o imaginário de um setor da população por um breve tempo. Depois, sua trajetória é mergulhada em um profundo silenciamento. A presença de Joãozinho da Gomeia tem visitado a cidade em uma "gangorra da memória", muito em função de certo isolamento e apropriação das memórias de Joãozinho da Gomeia nos seios de sua família religiosa que, desde os tempos de seu falecimento, tem sido marcada por uma série de conflitos e disputas. Contudo, as memórias isoladas e apropriadas por um grupo restrito não formam lembranças suficientes para sustentá-las por muito tempo, uma vez assim não são capazes de suscitar testemunhos que 


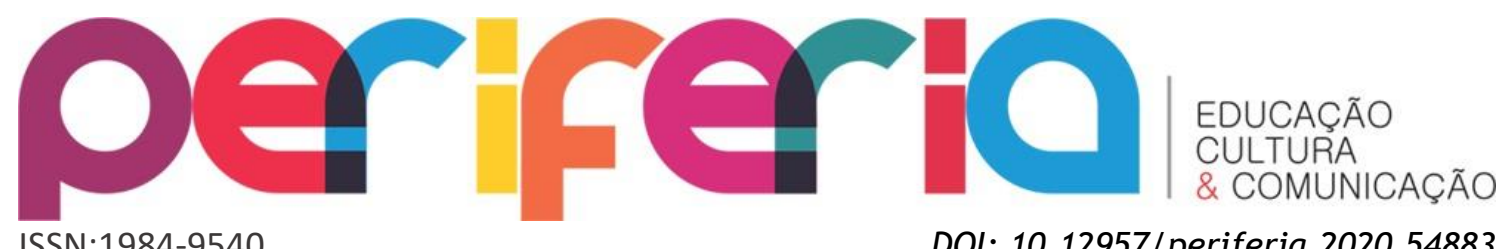

ofereçam apoio para fortalecê-las em um contexto mais amplo. As memórias coletivas se formam a partir da relação com o outro. Já dizia Maurice Halbwachs que toda a memória é coletiva. Mesmo as memórias individuais se constituem de quadros elaborados nas relações entre diferentes indivíduos de uma sociedade. Esses seriam os "quadros sociais da memória”, que servem como referências para a construção das lembranças de cada pessoas. São esses quadros que determinam o que se deveria lembrar, esquecer, silenciar ou comemorar pelas comunidades e indivíduos, considerando um contexto de quando e onde os episódios, acontecimentos e trajetórias se deseja rememorar (HALBWACHS, 2013). Portanto, a memória de Joãozinho da Gomeia sempre visitará o esquecimento enquanto não for vista como parte da “memória coletiva" da sociedade e do tempo em que ele viveu.

As inconstâncias de Joãozinho da Gomeia nas "memórias coletivas" da cidade de Duque de Caxias também se deram pela ausência de uma referência material, uma vez que desde a sua morte, o terreno e as construções onde funcionava a então famosa "Gomeia de Caxias" foram deteriorados ao longo do tempo, ao ponto de nem de perto lembrar a beleza e a grandiosidade de outras épocas. O terreno da antiga Gomeia de Caxias tornou-se um lugar de uma memória que se preferia esquecer, com um sentimento de derrota, o que não representava a imagem de um reino negro que se formou naquela localidade nas décadas entre 1940 e 1970.

\begin{abstract}
A curiosidade pelos lugares onde a memória se cristaliza e se refugia está ligada e este momento particular da nossa história. Momento de articulação onde a consciência da ruptura com o passado se confunde com o sentimento de uma memória esfacelada, mas onde o esfacelamento desperta ainda memória suficiente para que se possa colocar o problema de sua encarnação. O sentimento de continuidade torna-se residual aos locais. Há locais de memória porque não há mais meios de memória (NORA, 1993, p. 7).
\end{abstract}

Duque de Caxias é uma cidade monumentalizada. A sua paisagem urbana é marcada por muitos monumentos que foram transformados em lugares de memória e pautas de preservação patrimonial. Contudo, a monumentalização sempre manteve um lugar de privilégio para as memórias coloniais cultuadas

Periferia, v. 12, n. 3, p. 154-174, set./dez. 2020 


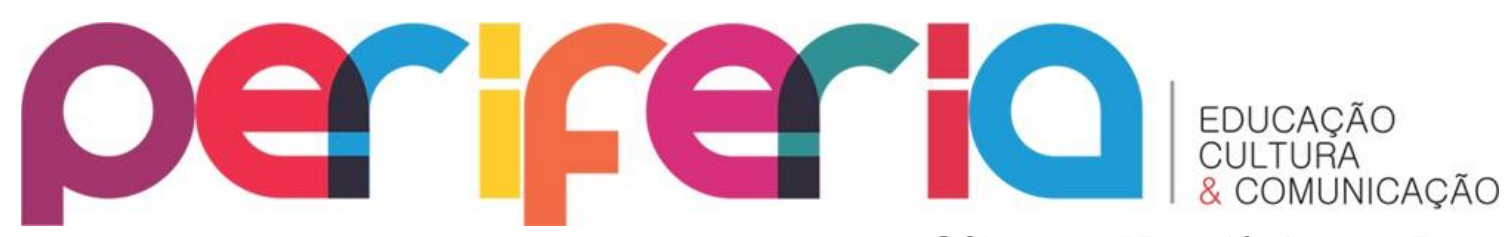

ISSN:1984-9540

DOI: $10.12957 /$ periferia. 2020.54883

pelas elites consagrando um sentimento de dominação e imposição das memórias coletivas construídas sobre as rememorações dos indivíduos que vivem na cidade. A memória de Joãozinho da Gomeia jamais foi monumentalizada. Algumas tentativas e projetos existentes em alguns momentos da "gangorra da memória" a que a personalidade de Joãozinho da Gomeia foi submetida, nunca foram concluídos.

Apesar das inconstâncias dos poderes constituídos, a memória de Joãozinho da Gomeia reaparece em alguns momentos. A lembrança e o esquecimento são os extremos conectados por um único eixo, formando uma "gangorra da memória", cujos tempo e contextos delimitam a sua dinâmica. Embora Joãozinho da Gomeia tem sido uma referência em seu tempo, talvez uma das personalidades da cidade mais famosa de sua época o processo de enquadramento da memória de Joãozinho da Gomeia ainda não foi estabelecido plenamente na "comunidade afetiva" da cidade de Duque de Caxias.

A despeito dos jogos e dinâmicas sociais que produziram os enquadramentos das memórias da cidade de Duque de Caxias, pode-se afirmar que, mesmo em "contextos subterrâneos", a memória de Joãozinho da Gomeia tem resistido ao longo do tempo:

Essas memórias subterrâneas que prosseguem seu trabalho de
subversão no silêncio e de maneira quase imperceptível afloram
em momentos de crise em sobressaltados e exacerbados. A
memória entra em disputa (...). O longo silêncio sobre o
passado, longe de conduzir ao esquecimento, é a resistência
que uma sociedade civil imponente opõe ao excesso de discurso
oficial. Ao mesmo tempo, ela transmite cuidadosamente as
lembranças dissidentes nas redes familiares e de amizades,
esperando a hora da verdade e da retribuição das cartas
políticas e ideológicas (POLLAK, 1989, p. 4).

O silêncio e o esquecimento de Joãozinho da Gomeia não representam uma completa derrota. Nas disputas das memórias esses momentos também são de resistência. Joãozinho da Gomeia se destacou como sacerdote do candomblé, quiçá ele foi o "rei do candomblé" em seu tempo. Sua existência foi e, agora, sua memória é de um lugar de resistência, identidade e pertencimento. Sendo o terreiro de candomblé, com seus rituais e crenças, 


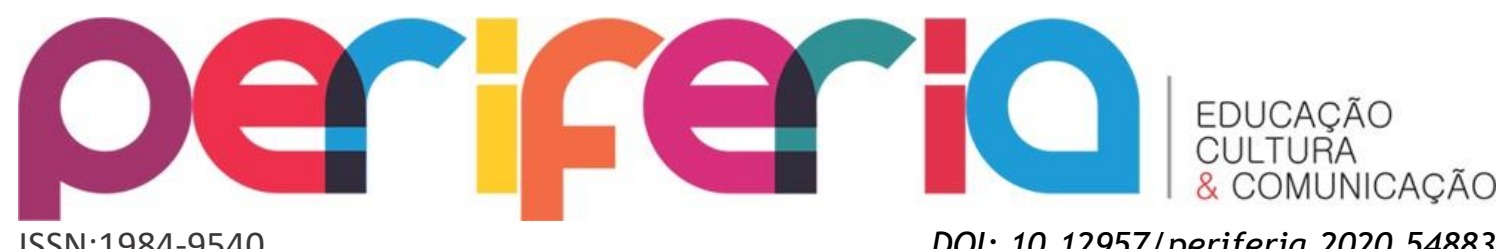

essencial para a construção das identidades das pessoas, a memória de "seu rei" também não fugiria de sua vocação para a elaboração das narrativas disputadas nos seios dos diferentes processos históricos da cidade de Duque de Caxias.

Com o crescimento dos espaços para os usos do candomblé em diferentes ambientes políticos do Brasil, a memória de Joãozinho da Gomeia também ganhou um contexto de reaparição. Os diferentes aspectos de sua trajetória ressurgiram em um momento quando os terreiros de candomblé em termos de patrimônio material e imaterial, passaram a ser compreendidos como lugares privilegiados de transmissão de conhecimentos tradicionais, religiosos, medicinais e de preservação de memórias ancestrais. Durante os primeiros anos do século XXI, Joãozinho da Gomeia reapareceu nos enquadramentos da memória de Duque de Caxias. Nesse contexto, uma dissertação de mestrado (PERALTA, 2000), uma monografia de licenciatura (NASCIMENTO, 2003) e um artigo (ISAAC, 2006) tornaram-se, senão as primeiras, as referências mais recorrentes para os estudiosos da cidade de Duque de Caxias. Contudo, o mais impactante foi a divulgação de materiais e peças relacionadas às suas memórias no acervo do Instituto Histórico da Câmara Municipal de Duque de Caxias. Desde 2001, o pesquisador Reizinho Lapoente prometia um documentário sobre Joãozinho da Gomeia. Em 2004, a proposta de criação de um Centro Cultural Joãozinho da Gomeia foi retomada no encontro "Africanidades Religiosas e a Cultura”, realizado no SESCI Caxias, com a organização da Secretaria Municipal de Cultura e a Fundação Palmares (GAMA, 2014). Contudo, as disputas das memórias têm muitas faces. Algumas delas provocaram um novo período de esquecimento. Em 2013, a Secretaria Municipal de Cultura, já em outro contexto da política municipal, mais uma vez anunciava um "novo projeto" para o enquadramento das memórias de Joãozinho da Gomeia. Um Centro de Cultura Afro-Brasileira Joãozinho da Gomeia era a pauta. Porém, a falta de uma visão realista sobre recursos e disposição política, além de muitas disputas por protagonismo, mais uma vez desenhava um novo período de limbo para as memórias de Joãozinho da Gomeia. Contudo, nesse contexto, um novo agente 


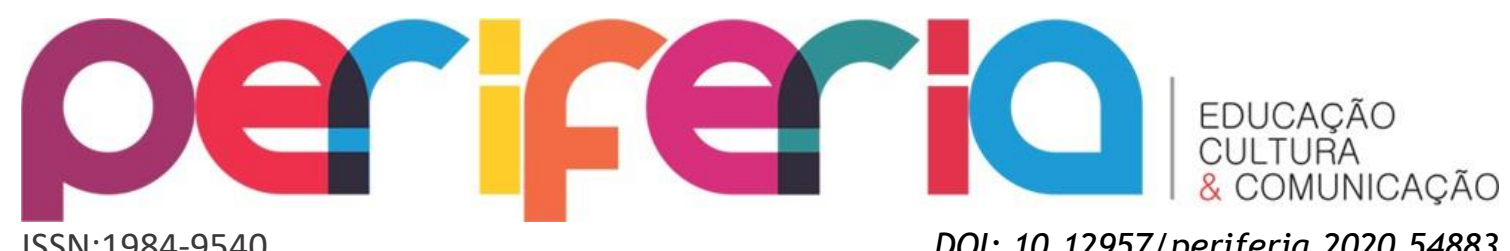

institucional surgiu nas disputas das memórias de Joãozinho da Gomeia: o Museu Vivo do São Bento.

O Museu Vivo do São Bento é o primeiro museu de percurso da Baixada Fluminense. A sua trajetória se iniciou bem antes de sua institucionalização com a perspectiva de oferecer protagonismo para as memórias das classes populares na história das cidades da Baixada Fluminense. Na década de 1990, um grupo de professores e pesquisadores da História da Baixada Fluminense se formou na Faculdade de Filosofia, Ciências e Letras de Duque de Caxias (FEUDUC). Entre seus propósitos estava a produção de uma nova historiografia para a Baixada Fluminense. Também havia o interesse de promover a preservação do patrimônio cultural no território, bem como construir um movimento de efetivação do ensino da história local e regional nas escolas da educação básica. Esse grupo organizou diferentes percursos históricos nas cidades da Baixada Fluminense, entre eles o que se realizava pelas ruas do bairro São Bento, que acabou dando origem ao museu.

O Museu Vivo do São Bento se consolidou em 2005, através das reivindicações do núcleo local do Sindicato Estadual dos Profissionais da Educação (SEPE). Naquele ano incluiu-se a criação do Centro de Referência Patrimonial e Histórica do Município de Duque de Caxias (CRPH-DC) e o circuito histórico do São Bento era projetado com um museu de percurso. Depois de longa negociação, com direito a greve, assembleias e atos públicos, o CRPH-DC foi criado pelo Decreto 4806, de 23 de dezembro de 2005, no âmbito da Secretaria Municipal de Educação de Duque de Caxias, já com o objetivo de dar condições para a fundação de um espaço museológico, de formação continuada, pesquisa e documentação da história local, além de elaboração de material didático para que fosse distribuído gratuitamente nas escolas públicas da cidade.

Incialmente, um projeto do CRPH-DC, o Museu Vivo do São Bento foi institucionalizado no âmbito da Secretaria Municipal de Educação de Duque de Caxias, por intermédio da Lei Municipal n 2224, de 03 de novembro de 2008. Era "um complexo museológico", isto é, um percurso de memória que contava com dez referências, tombadas pela mesma lei como lugares de memória e 


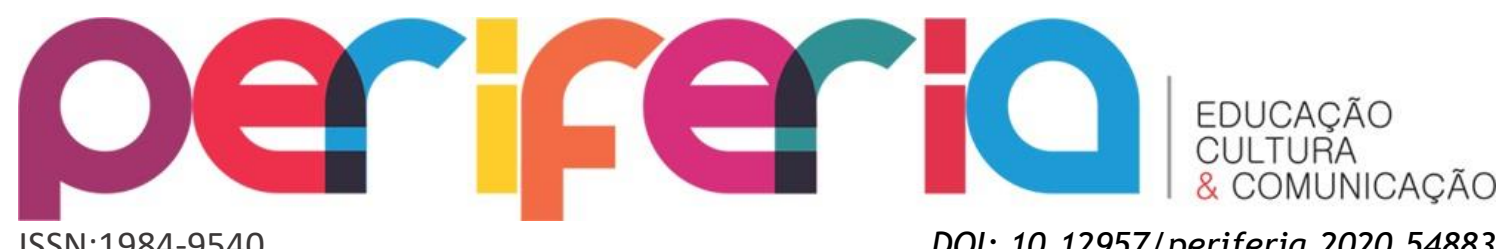

edificações patrimoniais, contudo sua existência não se restringe apenas ao percurso principal, sendo possível realizar os chamados percursos secundários, de forma que seja possível contemplar outras histórias, outras demandas e reivindicações populares de direito à memória (SILVA; SOUZA, 2009).

Fundamentado nas ideias da Museologia Social, o Museu Vivo do São Bento se propõe oferecer protagonismo para as memórias silenciadas nas disputas de narrativas da cidade. Joãozinho da Gomeia sempre foi tema do Museu Vivo do São Bento. Desde os primeiros tempos do CRPH-DC e do museu, a trajetória de Joãozinho da Gomeia e seu candomblé sempre foi tema de aulas e de oficinas oferecidas para os professores das redes públicas de Duque de Caxias. Bem antes da ideia de um memorial, a sua imagem já estava exposta no museu através de um quadro pintado por Barbosa Leite e que fora doado por um professor e militante de movimentos sociais depois de ser recuperado em uma das vias da cidade. Portanto, o Museu Vivo do São Bento encontrou e acompanhou Joãozinho da Gomeia desde a sua formação, mas até então, não tinha se colocado como protagonista nas disputas dessa memória e de suas narrativas.

\section{Joãozinho da Gomeia e seu centenário}

Em 2013, a equipe do Museu Vivo do São Bento foi convidada para participar de um seminário sobre Joãozinho da Gomeia que debateria a retomada do projeto do Centro de Cultura Afro-Brasileira Joãozinho da Gomeia, organizado por Jesus Chediak, então secretário municipal de cultura de Duque de Caxias. O seminário teve um caráter propositivo, mas ao final de seu expediente, notou-se que não ocorrera qualquer sistematização do projeto. Então, um integrante da equipe do Museu Vivo do São Bento lembrou que o ano seguinte seria o centenário de Joãozinho da Gomeia. Seria um bom momento para organizar comemorações e projetos relacionados ao "rei do candomblé", uma vez que seu João ainda era relegado nos enquadramentos da memória da cidade de Duque de Caxias. 


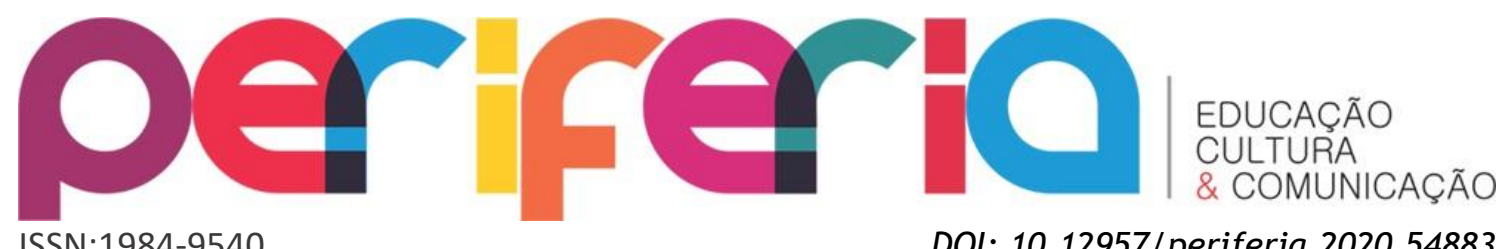

ISSN:1984-9540

DOI: $10.12957 /$ periferia.2020.54883

Como tudo o que se fazia sobre Joãozinho da Gomeia, o seminário também foi marcado por certa tensão. As disputas por legitimidade para ser guardião e representante das memórias da Gomeia sempre estiveram acirradas desde as tensões no processo de sucessão, por ocasião de seu falecimento em 1971. Por conta disso, a experiência do seminário apontava para a necessidade de um movimento de conciliação entre todos os postulantes à "agente autorizado" das memórias de Joãozinho da Gomeia. Porém, a ideia do centenário não seria um projeto do museu, mas da secretaria de cultura, inclusive com um possível lançamento da pedra fundamental e apresentação pública do Centro de Cultura Afro-Brasileira Joãozinho da Gomeia, que deveria ocorrer em 2014.

O tempo passou. Por aquele ano pouco se ouviu sobre Joãozinho da Gomeia, seja na mídia, em notas oficiais do governo municipal ou nas rodas de pesquisadores, mesmo com duas recentes dissertações de mestrado que foram defendias por aqueles tempos (MENDES, 2012; GAMA, 2012). Mesmo entre as casas de candomblé da cidade não se tem notícia de qualquer festejo em comemoração do seu centenário.

No Museu Vivo do São Bento, o ano de 2014 foi muito intenso. Com a aprovação de dois projetos financiados pela Fundação de Amparo à Pesquisa do Estado do Rio de Janeiro (FAPERJ), estabeleceu-se uma parceria com o Departamento de História da Faculdade de Filosofia, Ciências e Letras de Duque de Caxias (FEUDUC) e o Grupo de Pesquisa e Extensão Cultural A Cor da Baixada. Com isso, se organizou o curso de extensão Patrimônio, Memória e Cultura AfroBrasileira na Baixada Fluminense. Inicialmente planejado para uma turma de 40 professores de escolas públicas, o curso apresentou uma procura muito ampla. Em pouco tempo de divulgação, o curso formou uma turma de 150 inscritos entre professores, secundaristas, universitários, pesquisadores, militantes culturais, sacerdotes de candomblé, sambistas, mestres de capoeira, entre outros.

O curso foi organizado em quatro encontros mensais entre aulas públicas, mesas-redondas, estudos de campo e atividades de extensão cultural. Com início em março, a sua conclusão se daria em novembro. Portanto, foram nove 


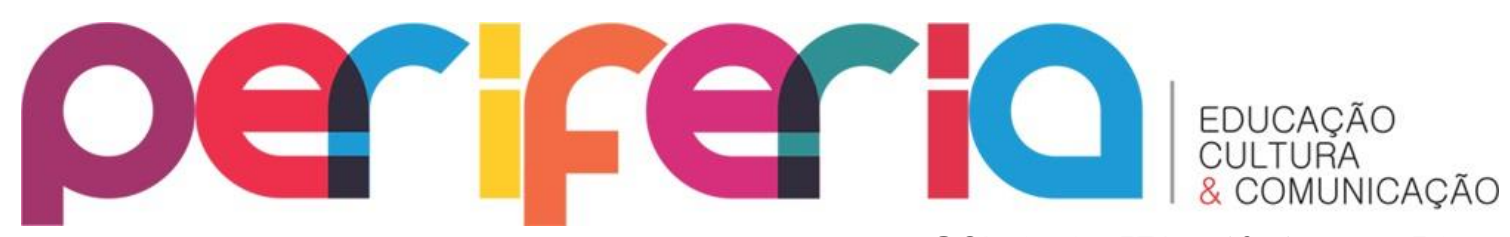

ISSN:1984-9540

DOI: $10.12957 /$ periferia. 2020.54883 meses de intensos debates sobre a história, a memória e o patrimônio de africanos e das culturas afro-brasileiras na Baixada Fluminense. Ao longo do curso debateu-se o tráfico e a escravidão, a liberdade e o pós-abolição, o movimento negro e as mais diferentes expressões da cultura afro-brasileira, como a capoeira, o candomblé, o carnaval e o samba. Em geral, o processo se dava com aulas teóricas às quintas e sábados, um debate público, às segundasfeiras e um estudo de campo no sábado seguinte.

Paralelamente ao curso, a equipe do Grupo de Pesquisa e Extensão Cultural A Cor da Baixada foi estruturando e realizando entrevistas com personalidades negras de Duque de Caxias, como os mestres de capoeira, sacerdotes do candomblé e militantes históricos do movimento negro. Além disso, no âmbito do projeto foi estabelecido que seria construído o Memorial Joãozinho da Gomeia no antigo terreno da Gomeia de Caxias, desde que a secretaria de cultura garantisse a limpeza, a terraplanagem e a segurança do local.

Oseias Casanova, um artista negro de Duque de Caxias, foi contratado para produzir um busto de ferro fundido que serviria de núcleo do memorial com o objetivo de promover uma monumentalização da memória de Joãozinho da Gomeia em Duque de Caxias. Além de fotografias e trechos de filmes antigos, também foram contactadas pessoas da família religiosa e referências negras que tiveram contato com o seu João ou que, pelo menos, tivesse maior familiaridade afetiva com sua memória. A primeira pessoa que atendeu ao chamado foi Silvia de Mendonça, antiga subsecretária de cultura e uma das responsáveis pelo primeiro projeto de Centro Cultural Joãozinho da Gomeia. Além disso, Silvia de Mendonça tem uma longa carreira como atriz, repórter e produtora cultural, o que sempre the ofereceu muito trânsito entre os militantes culturais da cidade. Foi através de Silvia de Mendonça que ocorreram as primeiras aproximações com a família religiosa da Gomeia em Duque de Caxias. Então, foi realizada uma visita à casa de dona Kitala Mugongo e de sua filha dona Seci Caxi, essa última considerada a herdeira espiritual de Joãozinho da Gomeia. Depois de uma breve conversa, elas atenderam ao convite para conhecer o ateliê de Oseias Casanova e conhecer o trabalho em curso para a 


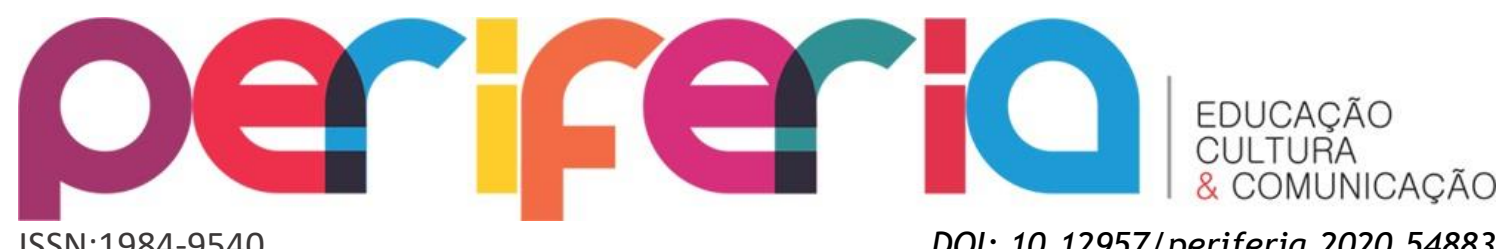

confecção do busto de Joãozinho da Gomeia. Essa visita foi muito emocionante!

Dona Kitala, uma das filhas mais próximas de seu João, ficou muito emocionada e perguntada por Oseias Casanova e estimulada por Silvia de Mendonça e por dona Seci Caxi, ela exclamou:

Está perfeito. Gostei! Está de parabéns! Lembrei dele e ele está aqui. Vocês não estão vendo, mas ele está aqui. Aquele é sr. Joãozinho da Gomeia. Ele foi e é. Deus levou, mas tem o nome dele aí na história. O nome dele na história. Parabéns para ele. Oxóssi que the dê tudo na sua vida e que não falte nada para você. (...). Era eu e ele, nós dois. (...). Sou baiana. Sou da Liberdade, de Salvador. (...). Eu era novinha, tinha 18 anos (...). Ele me mandou buscar. Eu vim de navio. Eu e Leci que me criou. Ela foi minha mãe criadeira. Ela tinha seis meses de santo. Oxóssi pegou ela para tomar conta de meu barco. Ela foi minha irmã de santo e minha mãe criadeira. Mas minha mãe pequena mesmo foi Nanganza do Bate Folha. Era nós duas, sempre juntas. Mas ele tinha mais coisa comigo do que ela porque eu era mais atirada que ela (...). Tudo! Se ele viajava, ele chegava na volta e me dava tudo (...) (KITALA MUGONGO, 2014).

Não havia qualquer sentido realizar um projeto do Centenário de Joãozinho da Gomeia sem qualquer diálogo com seus descendentes religiosos. Além disso, dona Kitala era uma das pessoas vivas que convivera cotidianamente com seu João. A ideia era que, caso ela fizesse alguma observação sobre as feições retratadas no busto, o artista plástico ainda teria tempo para fazer alterações. Porém, a sua reação e o seu depoimento ultrapassaram as intenções técnicas daquela visita, pois sua emoção contagiou a todos que estavam presentes no ateliê naquele dia. 0 processo de trânsito entre as individualidades e a memória coletiva estava sendo construída, independente de disputas e interesses diversos que sempre percorreram paralelamente aos projetos que envolviam as memórias de Joãozinho da Gomeia em Duque de Caxias.

Além da visita de dona Kitala, em outra oportunidade, José Zumba, uma referência do movimento negro e ex-vereador por dois mandatos também foi convidado para conhecer o ateliê e o busto de Joãozinho da Gomeia. Algumas autoridades, como o secretário de cultura e parte de sua equipe também fez a visita. Também ocorreram duas visitas de alunos do curso Patrimônio, Memória

Periferia, v. 12, n. 3, p. 154-174, set./dez. 2020 


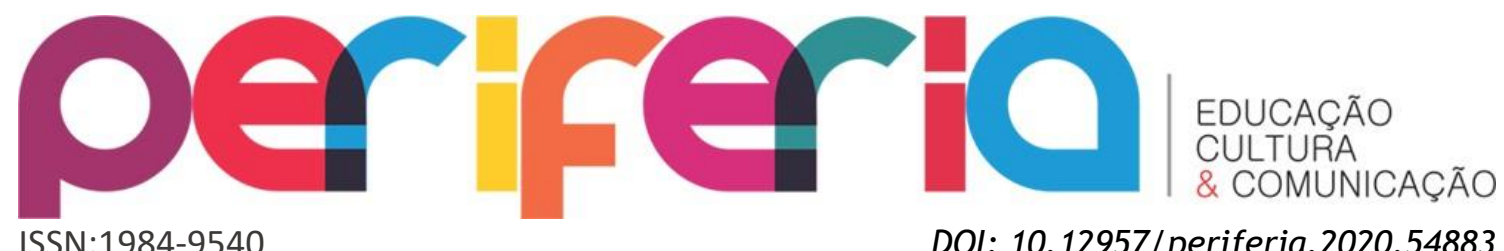

e Cultura Afro-Brasileira na Baixada Fluminense, como atividade pedagógica.

Entre os alunos, havia sacerdotes de candomblé, mestres de capoeira, professores e estudantes que puderam acompanhar o trabalho do artista plástico, bem como ter um acesso mais próximo da memória de Joãozinho da Gomeia para além das aulas teóricas e da visita ao abandonado terreno da antiga Gomeia de Caxias. A cada visita as feições de seu João se materializava, deixando de ser uma lembrança dispersa e se monumentalizava nos quadros da memória da cidade.

Além do busto e do memorial, também era necessário deixar um legado para o uso de professores nas suas aulas. O projeto previa a publicação de um livro e a edição de um documentário sobre a trajetória de Joãozinho da Gomeia. O caminho mais fácil era negociar a publicação de uma das dissertações de mestrado sobre seu João. O pesquisador Reizinho Lapoente foi convidado para participar do projeto com o lançamento de um documentário que ele estava produzindo. Infelizmente, a negociação sobre o documentário não aconteceu. Então, os recursos foram realocados e duas dissertações de mestrado foram editadas, tornando-se os primeiros livros sobre Joãozinho da Gomeia publicados em Duque de Caxias (MENDES, 2014; GAMA, 2014). De acordo com o planejamento, o curso terminaria com o lançamento dos livros e a inauguração do busto e do memorial de Joãozinho da Gomeia celebrando o seu centenário.

A segunda metade do curso transcorreu entre aulas, debates, estudos de campo e muita expectativa. Com a aproximação do fim do curso, havia um clima de grande envolvimento com a memória de Joãozinho da Gomeia. 0 anúncio da inauguração de um busto, um memorial e a publicação de dois livros sobre Joãozinho da Gomeia despertou o interesse de candomblecistas, intelectuais, militantes culturais e representantes do governo municipal. Era um processo de construção efetiva dos enquadramentos de Joãozinho da Gomeia nas memórias afetivas de Duque de Caxias. Esse processo se dava com uma estratégia política bem definida: envolver todos que fizessem qualquer reivindicação, crítica ou elogio sobre o projeto de Centenário de Joãozinho da Gomeia. De certa forma, havia algum tipo de mal estar, já que ao longo de 40 anos havia disputas pela legitimidade da memória de Joãozinho da Gomeia, mas

Periferia, v. 12, n. 3, p. 154-174, set./dez. 2020 


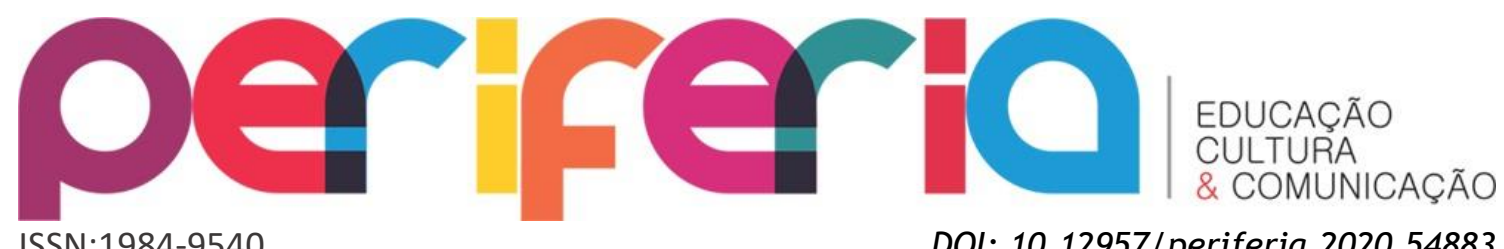

todos esses agentes que protagonizaram essas disputas deixaram passar o centenário de seu João sem qualquer tipo de comemoração ou menção honrosa, seja no campo das artes, da cultura ou da religiosidade.

A política de agregar todos demonstrou-se muito eficiente, pois os últimos meses do curso foram marcados por uma grande adesão de diferentes pessoas que procuravam o Museu Vivo do São Bento e o Grupo de Pesquisa e Extensão Cultural A Cor da Baixada para obter informações de como seria possível participar do evento de encerramento. As datas de 19 e 20 de novembro de 2014 foram marcadas para o encerramento do curso, entrega de certificados dos 98 alunos concluintes e a culminância do projeto. Naqueles dias haveria lançamento dos livros, feijoada, música, dança, exposição, além de uma homenagem aos sete mestres de capoeira que participaram efetivamente do curso ao longo de todo o ano. Embora a principal atividade do evento de encerramento fosse a inauguração do busto e do memorial, intrinsecamente estava posto que havia mais memórias e comemorações que coexistiam com seu João naquele dia. Uma forma de fortalecer a memória de Joãozinho da Gomeia, ao mesmo tempo que se amenizaria qualquer clima de disputas e tensões que visitava o projeto ao longo do ano. Além disso, uma comemoração do Centenário de Joãozinho da Gomeia não poderia deixar de ter música, dança, livros, capoeira, entre outros. Sem falar da presença de intelectuais, artistas, autoridades, professores, estudantes, mestres de cultura popular, entre outros. A festa não foi completa porque não houve candomblé. No interior da equipe do museu houve esse debate. Por ser um espaço público e com certo temor por alguma reação de intolerância religiosa essa ideia foi desconsiderada. Porém, os membros da família religiosa de seu João, puxados por dona Kitala, mesmo sentada em uma cadeira de rodas, fizeram cantos e preces em agradecimento à memória de Joãozinho da Gomeia. Diga-se de passagem, a família religiosa se fez presente com uma representação bem significativa, com a presença de Tata Anselmo (Bahia), Mãe Dango (São Paulo), Mãe Kitala e Mãe Ceci Caxi (Duque de Caxias). Também se registrou a presença de outros representantes da família da Gomeia do Rio de Janeiro, São Paulo, Bahia, Pernambuco, Minas Gerais, Paraná, entre outros. 


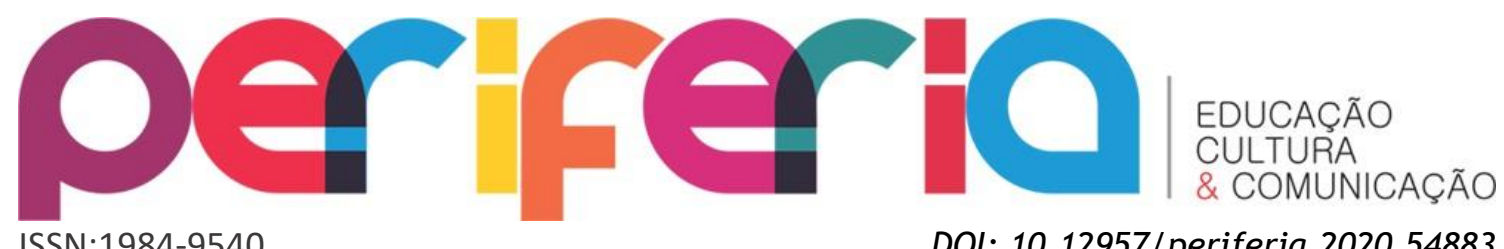

Embora não tenha sido possível instalar o memorial de Joãozinho da Gomeia no espaço de seu antigo terreiro, o busto foi inaugurado nos jardins do Museu Vivo do São Bento. Uma efetiva contribuição para o enquadramento de seu João nas memórias da comunidade afetiva de Duque de Caxias. 0 centenário tornou-se uma referência patrimonial para a comunidade acadêmica, para artistas e militantes da cultura. Também o centenário contribuiu para desmistificar a ideia de que era impossível ter acesso à família da Gomeia. A referência do centenário provocou uma série de evocações culturais e acadêmicas de Joãozinho da Gomeia, contribuindo para o seu enquadramento nas memórias da cidade.

\section{Joãozinho da Gomeia e as reverberações de uma memória centenária}

É claro que não se pode afirmar categoricamente que foi a monumentalização da memória de Joãozinho da Gomeia que suscitou todas as pesquisas acadêmicas, projetos políticos e produções culturais que se deram nos anos seguintes. Porém, coincidência ou não, todas as produções que ocorreram posteriormente ao centenário tiveram o envolvimento de indivíduos que estiveram ao longo do projeto do Centenário de Joãozinho da Gomeia que ocorreu no Museu Vivo do São Bento. Com isso, é possível pensar Joãozinho da Gomeia a partir da ideia de "memórias centenárias", que se caracteriza pelo rompimento das profundezas do esquecimento por sua importância, representatividade e por seus aspectos de longevidade. Nesse caso, o tempo também é resistência, considerando as dinâmicas e as preferências oficiais de uma perspectiva colonial para os enquadramentos da memória.

Ainda ao longo do Centenário de Joãozinho da Gomeia, a Fundação Palmares procurou o Museu Vivo do São Bento e o Grupo de Pesquisa e Extensão Cultural A Cor da Baixada para firmar parceria sobre uma atividade em que a fundação também pudesse se apresentar como organizadora do projeto. No dia primeiro de dezembro de 2014, a Fundação Palmares com o apoio do Museu Vivo do São Bento organizou o seminário Memória e Identidade - 100 anos de 


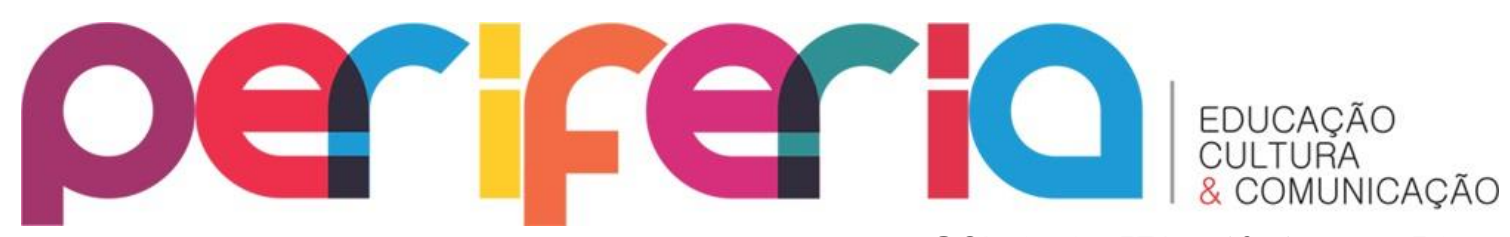

ISSN:1984-9540

DOI: $10.12957 /$ periferia. 2020.54883 Joãozinho da Gomeia realizado no plenário da Câmara Municipal de Duque de Caxias.

Já no ano de 2015, o Museu Vivo do São Bento e o Grupo de Pesquisa e Extensão Cultural A Cor da Baixada organizou outro curso "Patrimônios da Diáspora Africana na Baixada Fluminense", com uma programação bem parecida com o ano anterior. Porém, toda a chamada do curso de 2015 trazia a imagem do busto, com a intenção de que a memória de Joãozinho da Gomeia continuasse circulando no imaginário da cidade. Em agosto daquele ano o arqueólogo Rodrigo Pereira coordenou o projeto "Arqueologia de Terreiros" e as escavações do antigo terreno da Gomeia, ampliando o conhecimento sobre o passado do antigo terreiro de Caxias. Essas escavações foram amplamente divulgadas em blogs, jornais e redes sociais, o que contribuíram para que a memória de Joãozinho da Gomeia se mantivesse viva nas redes afetivas da cidade. Em novembro de 2015, o SESC-Caxias organizou o seminário: "Que rei é esse que veio da Gomeia?", dentro do projeto "IMÓ: o despertar da consciência", que contou com a ampla participação de alunos e professores das escolas públicas da cidade, uma vez que foi realizado em horário escolar e cuja estrutura contava com transporte para buscar e levar as pessoas entre a escola e o local do seminário. Ainda em 2015 foi lançado o projeto Galpão Criativo Gomeia, a primeira Co-Working Cultural da Baixada Fluminense que, situada em Duque de Caxias, também resolveu homenagear o centenário rei do candomblé, seu Joãozinho da Gomeia.

Em 2017, o jornalista Carlos Nobre lançou um livro sobre "a trajetória do mito Joãozinho da Gomeia" (NOBRE, 2017). Nesse mesmo ano, Thais Noronha anunciava a defesa de sua dissertação de mestrado "Joãozinho da Gomeia: memória do Babalorixá em Duque de Caxias (NORONHA, 2017). Em 2018, a jornalista Ana Carolina Pinheiro publicou uma longa reportagem sobre Joãozinho da Gomeia na Carta Capital, um periódico de grande circulação entre artistas e intelectuais do Brasil (PINHEIRO, 2018). Nesse ano, o arqueólogo Rodrigo Pereira iniciava a publicação de artigos com dados mais precisos dos resultados da escavação e indicava a defesa de sua tese de doutorado sobre esse tema em alguns anos (PEREIRA, 2018).

Periferia, v. 12, n. 3, p. 154-174, set./dez. 2020 


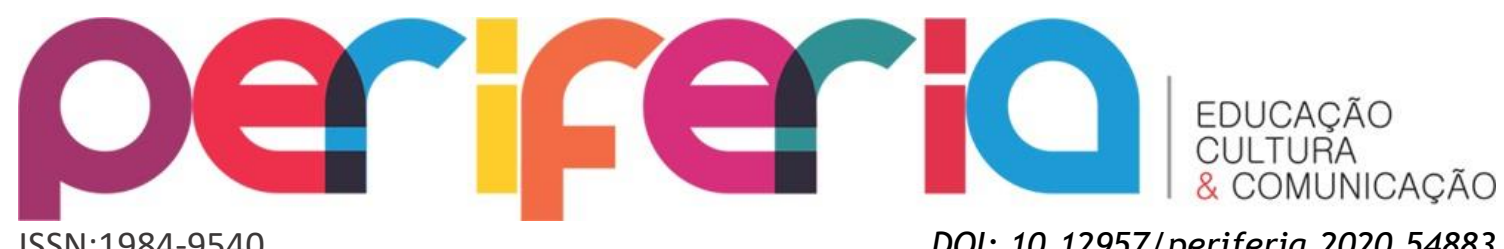

Em junho de 2019, a Escola de Samba Acadêmicos do Grande Rio anunciava que Joãozinho da Gomeia seria o enredo de 2020. O anúncio destacava os carnavalescos Gabriel Haddad e Leonardo Bora que desenvolveria o enredo Tata Londirá: o Canto do Caboclo no Quilombo de Caxias. Destacando que seria contada a trajetória de Joãozinho da Gomeia, pai de santo nascido na Bahia e que fez história em Duque de Caxias, se tornando um dos mais famosos líderes religiosos do Brasil (JUNIOR, 2019). Esse anúncio realmente exponenciou todos os impactos do processo de enquadramento da memória de Joãozinho da Gomeia em Duque de Caxias, pois as corriqueiras tensões foram suplantadas por um consenso generalizado. Por esse mesmo ano, a Faculdade de Educação da Baixada Fluminense (FEBF-UERJ) organizou um seminário com o tema “Joãozinho da Gomeia: educação, candomblé e carnaval”, contando com a presença de professores, alunos e os carnavalescos da Acadêmicos do Grande Rio. Esse ano também foi de lançamento do espetáculo “Joãozinho da Gomeia - de filho do tempo a Rei do Candomblé", dirigido e estrelado por Átila Bee (0 Dia, 18/06/2019). O ano de 2020, se iniciou com o carnaval da Grande Rio que mobilizou a cidade em torno da escola como há muito não se via. Era unânime entre todos que isso se dava pela escolha de Joãozinho da Gomeia como o tema do enredo. Nesse mesmo tempo, os cineastas Rodrigo Dutra e Janaina Oliveira anunciava o lançamento do filme Joãozinho da Gomeia, o rei do Candomblé que, meses mais tarde seria indicado para nove categoria no Festival de Gramado, o mais prestigiado do Brasil (CRUZ, 2020).

Os enquadramentos da memória nunca são retilíneos e consensuais. A comunidade afetiva e seus enquadramentos não garantem a inexistência de tensões entre a sociedade civil e os poderes constituídos. Joãozinho da Gomeia e suas memórias subterrâneas e representante de culturas minoritárias sempre estará sob ataque e vigilância, pois sua origem social sempre será vista em oposição à “memória oficial”. As disputas das memórias provocam reações, pois as memórias de uma cidade e suas narrativas representam um debate muito mais amplo que passa pelo poder simbólico que sustenta as forças políticas dominantes. Em junho de 2020, a Prefeitura Municipal de Duque de Caxias anunciou que o terreno da antiga Gomeia de Caxias seria utilizado para a 


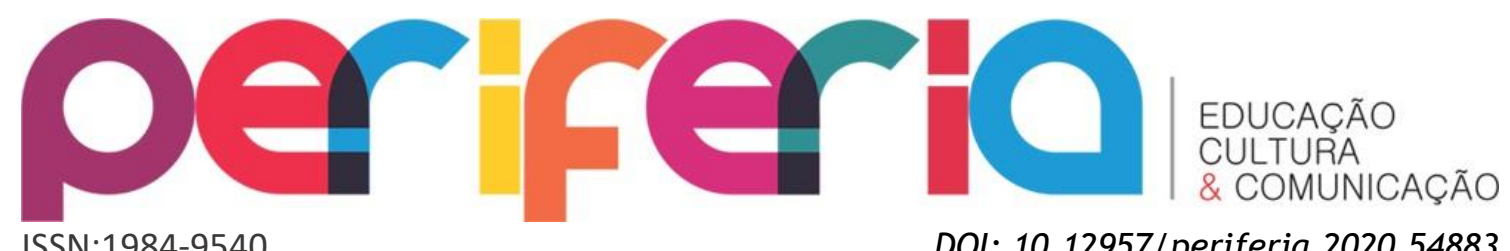

construção de uma creche, uma justa e antiga demanda da população daqueles arredores da cidade (BASSAN; BRASIL, 2020). Entretanto, a sociedade civil entrou na disputa mais uma vez. O Ministério Público foi acionado e ao Instituto Estadual do Patrimônio Cultural (INEPAC) foi feito um pedido de tombamento patrimonial em caráter de urgência para que o espaço fosse preservado para a construção do Centro de Cultura Afro-Brasileira Joãozinho da Gomeia (O DIA, 2020).

Mais uma vez o Museu Vivo do São Bento se fez presente no processo de enquadramento da memória de Joãozinho da Gomeia em Duque de Caxias. Por conta do contexto de pandemia, não foi possível organizar atividades que provocasse aglomerações. Sendo assim, foi organizada a Série Joãozinho da Gomeia que consistiu em 10 encontros virtuais que ocorreram entre 27 de julho e 21 de setembro. Ao longo desse período 22 pessoas, entre sacerdotes da família Gomeia, pesquisadores, artistas e gestores culturais debateram com a equipe do Museu Vivo do São Bento e com um amplo público que assistia e interagia pelas redes sociais da instituição.

Com a mobilização e as pressões sociais, culturais e judiciais, a Prefeitura de Duque de Caxias recuou e anunciou a construção da creche em outro terreno. Com o tombamento do antigo terreno da Gomeia Caxias como patrimônio do estado Rio de Janeiro, mais um importante passo será dado para que a memória de Joãozinho da Gomeia tem o reconhecimento cultural e social, mas que também seja definitivamente incorporado aos quadros da "memória oficial" da cidade de Duque de Caxias.

\section{Conclusão}

João Pedra Preta, Tata Londirá, Seu João ou Joãozinho da Gomeia são os nomes com que ficou conhecido João Alves Torres Filho. Nascido em 1914, Joãozinho da Gomeia teria uma trajetória comum de um menino nordestino negro do interior da Bahia, que na sua adolescência migrou para Salvador, a capital daquele estado e que, já em sua maturidade, se deslocou para o Rio de Janeiro, ainda a capital federal. Assim como muitos outros nordestinos que buscavam novas oportunidades na capital do país, Joãozinho da Gomeia também buscou em Duque de Caxias, na Baixada Fluminense, um refúgio contra

Periferia, v. 12, n. 3, p. 154-174, set./dez. 2020 


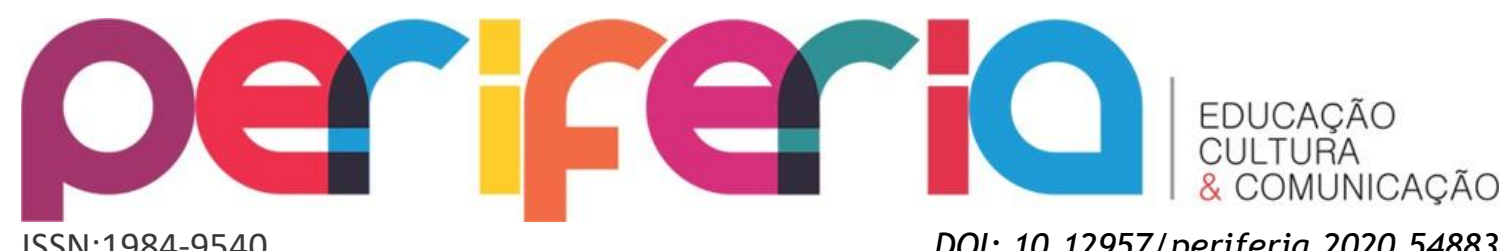

as adversidades que a cidade do Rio de Janeiro oferecia para a sua população durante a primeira metade do século XX. A sua vida em uma Duque de Caxias, que passava pela transição entre o espaço rural e o espaço urbano, foi extraordinária. A sua roça de candomblé, tornou-se a famosa Gomeia de Caxias, um lugar de concentração de familiares espirituais e simpatizantes, entre eles, autoridades políticas, artistas e intelectuais que se deslocavam da capital federal e se misturavam com a classe trabalhadora que vivenciava o cotidiano da cidade e daquela casa de candomblé. Além disso, sua fama ultrapassava os limites do candomblé, com destaque para sua atuação como músico, estilista, dançarino, entre outros. Joãozinho da Gomeia transformou Duque de Caxias em um lugar de procura e demanda com recorrentes multidões que procuravam as festas de seu terreiro e seus cuidados espirituais.

A morte de Joãozinho da Gomeia, em 1971, deu início a uma série de disputas por sua sucessão que provocou um processo de desagregação da Gomeia de Caxias, levando-a, algumas décadas depois, à verdadeira destruição e um processo de apagamento de seu João nos enquadramentos da memória da cidade. Ao longo de quatro décadas, a sua imagem passou por uma "gangorra da memória", com contextos e temporalidades de lembrança e esquecimentos. Somente no início do século XXI que as memórias de Joãozinho da Gomeia iniciaram um processo de reconhecimento nos quadros culturais da cidade, mesmo que ainda houvesse certas fragilidades no seu início.

Em 2014, com as comemorações do centenário, o Museu Vivo do São Bento organizou um processo de monumentalização das "memórias centenárias" de Joãozinho da Gomeia, produzindo um busto e memorial, publicação de livros e um intenso debate sobre seu João e sua importância para o patrimônio histórico de Duque de Caxias. As comemorações do centenário provocaram uma série de reverberações que se deram nos anos seguintes, com uma enorme repercussão entre os agentes culturais, líderes religiosos, intelectuais e autoridades políticas. As comemorações do centenário e as inciativas culturais e intelectuais que se seguiram intensificaram o debate sobre o tombamento patrimonial da memória de Joãozinho da Gomeia, em função de suas “memórias centenárias" caracterizadas não apenas por sua grandiosidade,

Periferia, v. 12, n. 3, p. 154-174, set./dez. 2020 


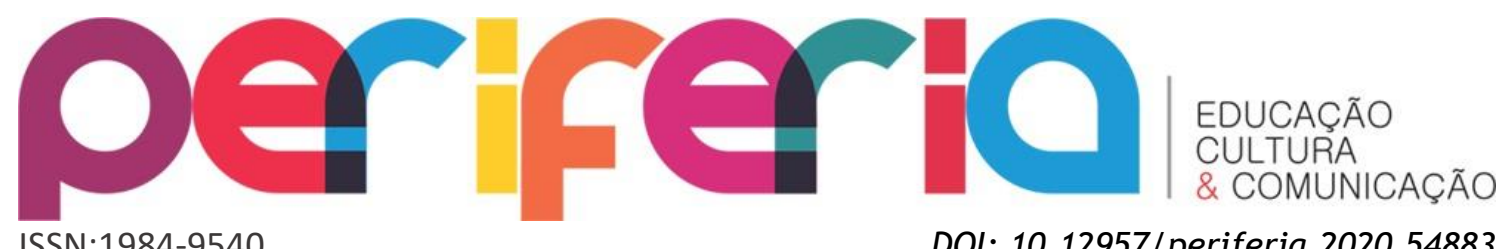

ISSN:1984-9540

DOI: $10.12957 /$ periferia. 2020.54883

mas também por sua longevidade e resistência nas tensões e disputas políticas e culturais da cidade.

A relação entre o Museu Vivo do São Bento e as memórias de Joãozinho da Gomeia representa um projeto político de memória, história e patrimônio da cultura e das classes populares que formaram a cidade de Duque de Caxias. Desse modo, identifica-se uma narrativa de decolonização da memória da cidade em curso. Portanto, as “memórias centenárias" de Joãozinho da Gomeia não representam apenas o reconhecimento do indivíduo, mas um diferente projeto de memória coletiva para a cidade de Duque de Caxias, em oposição as tradicionais memórias cultivadas pelos discursos oficiais ao longo de sua história.

\section{REFERÊNCIAS}

BASSAN, Pedro; BRASIL, Marcia. Duque de Caxias anuncia construção de creche em terreno considerado sagrado pelo candomblé. G1, 16 de julho de 2020.

BEZERRA, Nielson Rosa. Nas sombras da diáspora: patrimônio e cultura afrobrasileira na Baixada Fluminense. Duque de Caxias: APPH-CLIO/INEPAC, 2013.

CRUZ, Cintia. Filme de babalorixá mais famoso da Baixada Fluminense vai disputar nove categorias no Festival de Gramado. Extra, 13 de agosto de 2020. Disponível em https://extra.globo.com/noticias/rio/filme-sobre-babalorixamais-famoso-da-baixada-fluminense-vai-disputar-nove-categorias-emgramado-rv1-1-24583230.html

FERNANDES, Florestan. A integração do negro na sociedade de classes. São Paulo: Globo, [1965] 2008.

FOLHA DA CIDADE. Autoridades discutem um tombamento do Terreiro de Joãozinho da Gomeia, 20 de fevereiro de 2004.

GAMA, Elizabeth Castelano. Mulato, homossexual e macumbeiro: que rei é este? Trajetória de João da Gomeia. Dissertação de Mestrado em História. Niterói: UFF, 2012.

GAMA, Elizabeth Castelano. Mulato, homossexual e macumbeiro: que rei é este? Trajetória de Joãozinho da Gomeia (1914-1971). Duque de Caxias: APPH-CLIO, 2014.

GAMA, Elizabeth Castelano. Um rei negro na Baixada Fluminense: memória e esquecimento. Periferias, v. 6, p. 101-119, 2014.

Periferia, v. 12, n. 3, p. 154-174, set./dez. 2020 


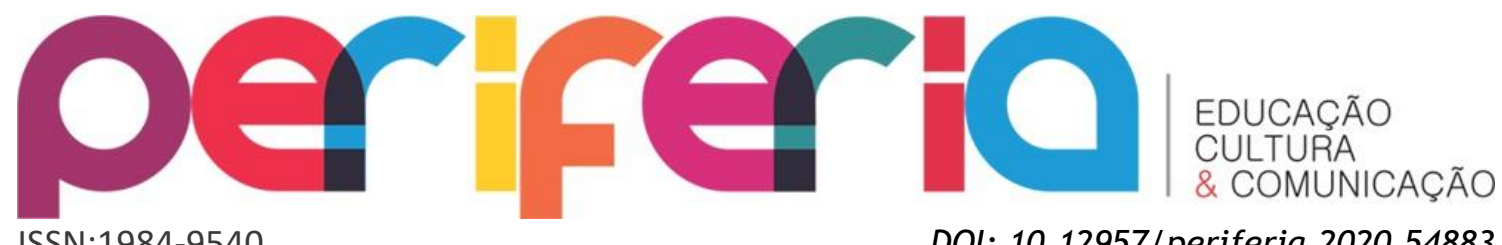

ISSN:1984-9540

DOI: $10.12957 /$ periferia.2020.54883

HALBWACHS, Maurice. A memória coletiva. Tradução de Beatriz Sidou. $2^{\mathrm{a}}$ ed. São Paulo: Centauro, 2013.

IBGE. Censo Demográfico. Rio de Janeiro: IBGE, 2010.

ISAAC, Daniel. 0 candomblé na Baixada Fluminense. Revista Pilares, v.4, n. 6, p. 49-69, 2006.

JUNIOR, David. Joãozinho da Gomeia será o enredo da Grande Rio em 2020.

Portal Carnaval, 20 de junho de 2019. Disponível em

https://portalcarnaval.com.br/joaozinho-da-gomeia-sera-o-enredo-dagrande-rio-em-2020/

KITALA MUNGONGO. Depoimento (2014). Busto João da Gomeia por Casanova. Disponível em https: / / www.youtube.com/watch?v=5-CPcYNz8dw

MENDES, Andrea. Vestidos da realeza: contribuições centro-africanas no Candomblé de Joãozinho da Gomeia (1937-1967) - Dissertação de Mestrado em História. Campinas: UNICAMP, 2012.

MENDES, Andrea. O Rei do Candomblé nas páginas da Revista: Joãozinho da Gomeia em O Cruzeiro (1967). Revista Recôncavo, v.4, n.6, p. 58-78.

MENDES, Andrea. Vestidos de realeza: fios e nós centro-africanos no candomblé de Joãozinho da Goméia. Duque de Caxias: APPH-CLIO, 2014.

NASCIMENTO, Andréa dos Santos. Joãozinho da Gomeia: de São Caetano a Caxias. TCC de Licenciatura Plena em História. Rio de Janeiro: UERJ, 2003.

NOBRE, Carlos. Joãozinho da Gomeia: a arte de tecer o invisível. Rio de Janeiro: Centro Portal Cultural, 2017.

NORA, P. Entre memória e história. A problemática dos lugares. Projeto História, São Paulo: PUC, n. 10, p. 7-28, 1993.

NORONHA, Thais Fernanda. Joãozinho da Gomeia: memória do Babalorixá em Duque de Caxias. Dissertação de Mestrado em Humanidades. Duque de Caxias: UNIGRANRIO, 2017.

O DIA. Joãozinho da Gomeia vira tema de peça em Caxias, 18 de junho de 2019. Disponível em https://odia.ig.com.br/duque-de-

caxias/2019/06/5654552-joaozinho-da-gomeia-vira-tema-de-peca-em-duquede-caxias.html

O DIA. Primeira vistoria para o tombamento do terreiro da Gomeia acontece nesta sexta-feira, 31 de julho de 2020. Disponível em https://odia.ig.com.br/duque-de-caxias/2020/07/5961814-primeira-vistoriapara-tombamento-do-terreiro-da-gomeia-acontece-nesta-sexta.html\#foto=1

Periferia, v. 12, n. 3, p. 154-174, set./dez. 2020 


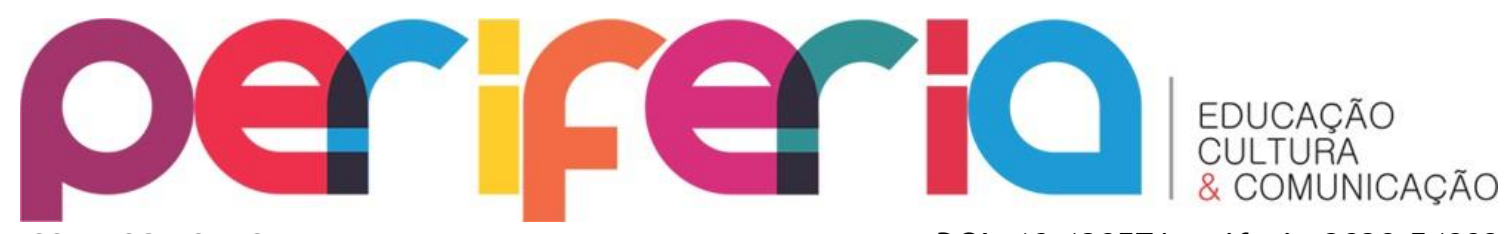

ISSN:1984-9540

DOI: $10.12957 /$ periferia. 2020.54883

PINHEIRO, Ana Carolina. Joãozinho da Gomeia, o rei do Candomblé. Carta Capital, 25 de julho de 2018. Disponível em

https://www.cartacapital.com.br/diversidade/joaozinho-da-gomeia-o-rei-docandomble/

PERALTA, Antônio Carlos Lopes. Um Vento de Fogo. Dissertação de Mestrado em História. Vassouras: USS, 2000.

PEREIRA. Rodrigo; CHEVIATARESE, A. L. Espaço e representações sociais: a residência de Joãozinho da Gomeia e os discursos sobre homossexualidade e poder em um terreiro de candomblé. Revista de Estudos sobre o Jesus Histórico e sua Recepção, v. 21, p. 95-124, 2018.

PEREIRA, R. Vozes, Concreto e Memórias: a etnografia no extinto Terreiro da Gomeia (Duque de Caxias/RJ). Norus - Novos Rumos Sociológicos, v. 6, p. 434469, 2018.

PEREIRA, R. Materiais Plásticos e Arqueologia: um estudo de caso a partir do Sítio Arqueológico do Terreiro da Gomeia (Duque de Caxias/RJ). Revista de Arqueologia Pública, v. 12, p. 3-30, 2018.

POLLAK, Michael. Memória, esquecimento, silêncio. Revista Estudos Históricos, v.2, n.3, p. 3-15, 1989.

SANT'ANNA, Márcia. 0 tombamento de terreiros de candomblé no âmbito do IPHAN: critérios de seleção e de intervenção. In: AMORIM, Carlos A., et all. Políticas de Acautelamento do IPHAN para Templos de Culto Afro-Brasileiros. Salvador: IPHAN, 2012.

SILVA, Marisa Gonzaga; SOUZA, Marlúcia Santos. Os professores e a construção do eco-museu no município de Duque de Caxias (RJ): um relato de experiência". In: PEREZ, Carmen Lucia Vidal; TAVARES, Maria Tereza Goudard; ARAUJO, Mairce da Silva. (Org.) Memória e patrimônios; experiências em formação de professores. Rio de Janeiro: EdUERJ, 2009.

Periferia, v. 12, n. 3, p. 154-174, set./dez. 2020 